\title{
GAIA Level 3b Prenatally Diagnosed Congenital Microcephaly
}

National Cancer Institute

\section{Source}

National Cancer Institute. GAIA Level 3b Prenatally Diagnosed Congenital Microcephaly. NCI Thesaurus. Code C128765.

GAIA Level 3B Prenatally Diagnosed Congenital Microcephaly is defined by three criteria: first, the fetus is at least 24 weeks gestational age (GA), with GA based on certain or uncertain last menstrual period (LMP) date, with fundal heig ht and no confirmatory first or second trimester ultrasound (US) scan, OR uncertain LMP with second trimester ultrasound, intrauterine insemination (IUI) OR embryo transfer date; second, a head circumference (HC) measurement either 2 standard deviations (SD) below the mean or less than the third percentile according to fetal US examination, using appropriate, standardized reference charts according to GA and gender for the population (e.g. WHO growth reference charts if GA greater than or equal to 37 weeks and Interg rowth-21st reference charts for GA 24 to 36 weeks); third, no confirmation of microcephaly with any additional US or by $\mathrm{HC}$ measurement at either birth or autopsy. 